\title{
EDITORIAL
}

\section{Should all ICU clinicians regularly be tested for burnout? We are not sure}

\author{
Conceptual considerations that precede screening for burnout syndrome in ICU clinicians
}

Meredith Mealer ${ }^{1 *}$ (1) and Marc Moss ${ }^{2}$

(c) 2018 Springer-Verlag GmbH Germany, part of Springer Nature and ESICM

The Intensive Care Medicine editors assigned us the unenviable task of explaining that we are not sure whether all ICU clinicians should be regularly screened for burnout syndrome. We will defend this position by posing four questions that should be answered before determining whether screening for burnout syndrome is beneficial or not for ICU clinicians.

\section{Question 1: Is burnout syndrome the proper disorder to screen for in ICU clinicians?}

Burnout syndrome originated from pragmatic workplace concerns including the loss of motivation and diminishing job satisfaction that are related to prolonged exposure to work-related stress. Though a variety of diagnostic criteria currently exist, burnout syndrome is most often defined as a state of emotional exhaustion caused by emotionally demanding work-related situations or the failure to achieve an expected goal or outcome for a client or patient $[1,2]$. ICU clinicians are frequently exposed to situations that intertwine their knowledge, skills, and values with life and death situations. However, screening for burnout syndrome alone may not be the best approach as ICU clinicians can develop a myriad of complex psychological disorders. For example, approximately $25 \%$ of ICU nurses have symptoms of post-traumatic stress disorder (PTSD) and $18 \%$ fulfill the diagnostic criteria for PTSD using the post-traumatic diagnostic scale (PDS) [3, 4]. Symptoms of anxiety and depression are also prevalent in ICU nurses with estimates ranging from $11 \%$ to $60 \%[3,4]$.

\footnotetext{
*Correspondence: Meredith.Mealer@ucdenver.edu

${ }^{1}$ Department of Physical Medicine and Rehabilitation, University

of Colorado Anschutz Medical Center, University of Colorado School

of Medicine, 12631 E. 17th Ave. F493, Aurora, CO 80045, USA

Full author information is available at the end of the article
}

For contrasting viewpoints, please go to https://doi.org/10.1007/s00134018-5094-z and https://doi.org/10.1007/s00134-018-5139-3.

Institution where the work was performed: University of Colorado Denver.
Screening for symptoms will raise awareness about burnout syndrome in ICU healthcare providers, and could be an important benchmark for unit administrators. However, the proper diagnostic criteria of burnout syndrome need to be utilized correctly. The diagnostic criteria for burnout include subjective and objective factors and recommendations that the symptoms should not result from (1) being a novice ICU clinician; (2) major psychological symptoms or disorders; or (3) non-workrelated family problems [5]. Considering the significance of other psychological disorders and the absence of comprehensive instruments to measure clinician expertise and stressful events experienced outside of the workplace, the utility of screening for burnout syndrome alone needs to be more carefully examined.

\section{Question 2: What are the best survey instruments to screen for burnout in ICU clinicians?}

Several instruments can screen and identify individuals with symptoms of burnout. Because of the vagueness and the potential overly sensitive diagnostic criteria of these burnout instruments, their utility is relatively unclear in the ICU setting. The Burnout Measure (BM) and the Maslach Burnout Inventory (MBI) are two instruments with extensive psychometric analyses. Collectively, these instruments have been tested in a large sample of subjects $(\sim 12,000)$ with adequate reliability and validity. However, there is questionable validity of these instruments, based on confirmatory factor analyses in the ICU setting. Additionally, these measures do not validly distinguish symptoms of burnout syndrome from related situations such as depression $[6,7]$ and job dissatisfaction [8].

Some triggers for burnout syndrome exist across acute healthcare providers such as mandatory overtime, inexperienced providers, arguments, improper training, and pettiness. However, the ICU setting may be sufficiently

\section{实




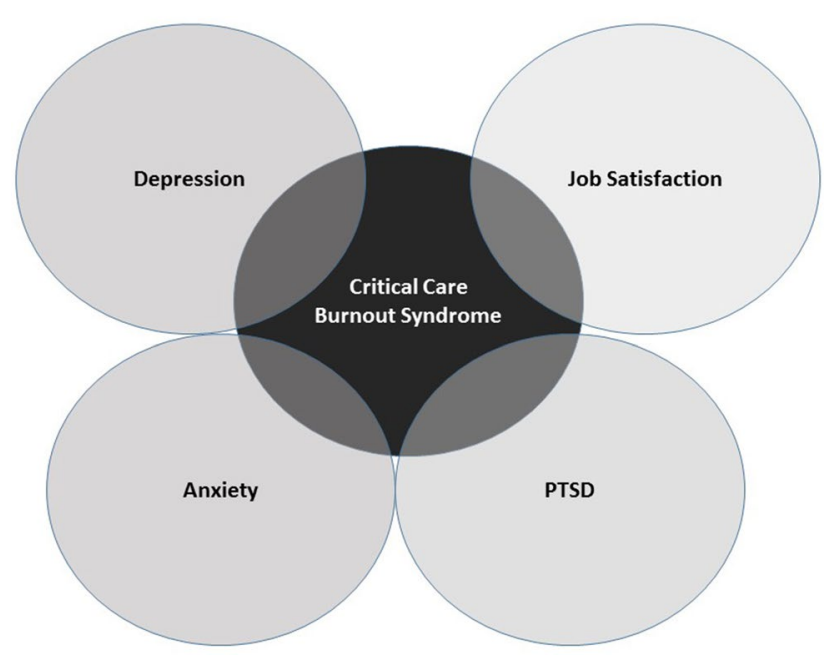

Fig. 1 Burnout syndrome construct overlap

different from most other work environments to warrant an adapted version of existing instruments. ICU-specific triggers of burnout syndrome include patient deaths, performing CPR, the stress of multiple monitoring alarms, and assisting family members through traumatic situations [9]. Similarly, these ICU-specific triggers are not exclusive to burnout syndrome and overlap with symptoms of depression, anxiety, and PTSD in ICU clinicians $[4,10]$ (Fig. 1). One potential solution is to refine the reliability and validity of the current instruments and to concurrently measure depression, anxiety, and PTSD, instead of developing a burnout tool unique to the ICU.

\section{Question 3: How should the stigma associated with burnout and other psychological disorders be addressed?}

Based on the DSM-V criteria, burnout syndrome is not considered a mental illness diagnosis but a subcategory of adjustment disorders [5]. The fear of being labeled, discriminated against, or perceived to not be able to adequately care for patients may result in clinicians being hesitant to truthfully answer burnout questionnaires. Before routine screening for burnout syndrome can occur, the stigma associated with burnout needs to be addressed. ICU providers need to feel comfortable sharing their psychological symptoms and distress. Education and resources dedicated to burnout syndrome may help alleviate self-stigma, peer stigma, and systemlevel stigma that prevent clinicians from acknowledging and seeking the appropriate care for symptoms of burnout. Education approaches to stigma change are often augmented by strategic interactions between respected thought leaders in the field who have experienced the specific symptoms (in this case of burnout) and targeted individuals in the community (in this case the community of ICU clinicians) [11].

\section{Question 4: Are we properly prepared to utilize the results of burnout testing to help ICU providers?}

The recent Call to Action from the Critical Care Societies Collaborative emphasizes the priorities of raising awareness and identifying strategies to mitigate symptoms of burnout in ICU clinicians [12]. However, raising awareness is only an important first step in combatting the epidemic of burnout in ICU providers. Screening for symptoms of burnout alone is unlikely to address the problem effectively. Organizational and individualize strategies should already be in place and available for those providers who screen positive for symptoms of burnout. In addition, the time required to participate in these programs cannot be viewed as an additional burden to the healthcare providers. Otherwise, providers will not choose to access and utilize the available resources. As it is unlikely that one strategy will be effective for all providers, hospital administrators and university leadership collectively need to prioritize the appropriation of resources for a variety of strategies to combat burnout. In addition, these groups could also provide funding for burnout-related research to develop and test novel and effective individual and organizational strategies to reduce burnout symptoms in ICU providers.

\section{Author details}

${ }^{1}$ Department of Physical Medicine and Rehabilitation, University of Colorado Anschutz Medical Center, University of Colorado School of Medicine, 12631 E. 17th Ave. F493, Aurora, CO 80045, USA. ${ }^{2}$ Division of Pulmonary Sciences 
and Critical Care Medicine, Department of Medicine, University of Colorado School of Medicine, Aurora, CO, USA.

Received: 24 January 2018 Accepted: 7 April 2018

Published online: 7 May 2018

\section{References}

1. Freudenberger HJ (1974) Staff burnout. J Soc Issues 30:159-165

2. Maslach C (1976) Burned-out. Hum Behav 5:16-22

3. Mealer M, Burnham E, Goode C, Rothbaum B, Moss M (2009) The prevalence and impact of posttraumatic stress disorder and burnout syndrome in nurses. Depression Anxiety 26:1118-1126

4. Mealer M, Jones J, Newman J, McFann K, Rothbaum B, Moss M (2012) The presence of resilience is associated with a healthier psychological profile in intensive care unit (ICU) nurses: results of a national survey. Int J Nurs Stud 49:292-299

5. Bibeau G, Dussault G, Larouche LM, Lippel K, Saucier JF, Vezina M, Vidal JM (1989) Certains aspects culturels, diagnostiques et juridiques de burnout [Some cultural diagnostic and juridical aspects of burnout]. Confederation des Syndicats Nationaux, Montreal
6. Firth H, Mclntee J, McKeown P, Britton PG (1986) Burnout and professional depression: related concepts? J Adv Nurs 11:633-641

7. Landsbergis PA (1988) Occupational stress among health care workers: a test of the job-demands model. J Occup Behav 9:217-239

8. Schaufeli W, Maslach C, MarekT (eds) (2017) Professional burnout: recent developments in theory and research. Routledge, New York

9. Mealer M, Hodapp R, Conrad D, Dimidjian S, Rothbaum B, Moss M (2017) Designing a resilience program for critical care nurses. AACN Adv Crit Care 28:359-365

10. Mealer M, Shelton A, Berg B, Rothbaum B, Moss M (2007) Increased prevalence of post-traumatic stress disorder symptoms in critical care nurses. Am J Respir Crit Care Med 175:693-697

11. Corrigan PW, Druss BG, Perlick DA (2014) The impact of mental illness stigma on seeking and participating in mental health care. Assoc Psychol Sci 15:37-70

12. Moss M, Good V, Gozal D, Kleinpell R, Sessler C (2016) A Critical Care Societies Collaborative statement: burnout syndrome in critical care health-care professionals. Am J Respir Crit Care Med 194:106-113 